\title{
Educação em saúde acerca da violência contra a mulher: um relato de experiência
}

\author{
Health education about violence against women: an experience report
}

Educación para la salud sobre la violencia contra las mujeres: un informe de experiencia

Hyslla Maria de Oliveira Barros ${ }^{1 *}$, Alizandra Mendonça Reis ${ }^{1}$, Maria Inês Vieira de Oliveira Lima ${ }^{1}$, Mônica Custódia do Couto Abreu Pamplo², Ivonete Vieira Pereira Peixoto¹.

\section{RESUMO}

Objetivo: Socializar experiência educativa em saúde, desenvolvida em prática curricular em Saúde Coletiva do curso de graduação em enfermagem, abordando a Violência Contra a Mulher (VCM). Relato de experiência: A ação foi realizada por acadêmicos do $7^{\circ}$ período do curso de bacharelado em Enfermagem de uma faculdade do Estado do Pará, no qual foi realizada em uma Unidade Municipal de Saúde (UMS). As participantes foram mulheres usuárias do Sistema Único de Saúde (SUS), faixa etária entre 18 anos a 40 anos, que se encontravam na sala de espera para coleta do exame preventivo. A ação foi realizada utilizando tecnologias leves buscando facilitar o entendimento e estimular a participação das mulheres. Considerações finais: Por ser a atenção básica a porta de entrada do Sistema de Saúde ressalta-se a importância de realizar ações educativas para melhor atendimento das políticas pública a saúde das mulheres, esclarecimento sobre Violência Contra Mulher, minimizando índices de morbimortalidade feminina.

Palavras-chave: Educação em saúde, Prevenção, Violência doméstica.

\begin{abstract}
Objective: Socialize educational experience in health, developed in curricular practice in Collective Health of the undergraduate nursing course, addressing Violence Against Women (VCM). Experience report: The action was carried out by academics from the 7th period of the Bachelor of Nursing course at a college in the State of Pará, in which it was held at a Municipal Health Unit (UMS). The participants were women users of the Unified Health System (SUS), aged between 18 and 40 years old, who were in the waiting room to collect the preventive exam. The action was carried out using light technologies seeking to facilitate understanding and encourage the participation of women. Final considerations: Because primary care is the gateway to the Health System, the importance of carrying out educational actions to better meet public policies on women's health, clarification on Violence Against Women, minimizing female morbidity and mortality rates is emphasized.
\end{abstract}

Keywords: Health education, Prevention, Domestic violence.

\section{RESUMEN}

Objetivo: Socializar la experiencia educativa en salud, desarrollada en la práctica curricular en Salud Colectiva de la carrera de Licenciatura en Enfermería, abordando la Violencia contra la Mujer (VCM). Informe de experiencia: La acción fue realizada por académicos del 7 mo período de la carrera de Licenciatura en Enfermería en una facultad del Estado de Pará, en la cual se realizó en una Unidad Municipal de Salud (UMS).

${ }^{1}$ Centro Universitário do Estado do Pará (CESUPA), Belém - PA. *E-mail: hysllamaria06@gmail.com

2 Universidade Federal do Estado do Pará (UFPA), Belém - PA. 
Los participantes fueron mujeres usuarias del Sistema Único de Salud (SUS), con edades entre 18 y 40 años, que se encontraban en la sala de espera para recoger el examen preventivo. La acción se llevó a cabo utilizando tecnologías ligeras buscando facilitar el entendimiento y fomentar la participación de las mujeres. Consideraciones finales: Debido a que la atención primaria es la puerta de entrada al Sistema de Salud, se enfatiza la importancia de realizar acciones educativas para cumplir mejor con las políticas públicas de salud de la mujer, aclaración sobre la Violencia contra la Mujer, minimizando las tasas de morbilidad y mortalidad femenina.

Palabras clave: Educación en salud, Prevención, Violencia doméstica.

\section{INTRODUÇÃO}

A Constituição Federal, em seu art. 226, parágrafo $8^{\circ}$, certifica "a assistência à família, na pessoa de cada um dos que a integram, criando mecanismos para coibir a violência, no âmbito de suas relações". Dessa forma, o Estado brasileiro assume um papel no enfrentamento a qualquer tipo de violência, seja ela praticada contra homens ou mulheres, adultos ou crianças (BRASIL, 2001).

No Brasil, a abordagem da violência como problema de saúde foi institucionalizada em 2001, por meio da Política Nacional de Redução da Morbimortalidade por Acidentes e Violências, dando-se ao termo definição bastante semelhante, a saber, todo "evento representado por ações realizadas por indivíduos, grupos, classes, nações, que ocasionam danos físicos, emocionais, morais e ou espirituais a si próprio ou a outros" (BRASIL, 2001).

No dia 08 de agosto de 2006, foi promulgada a Lei $n^{\circ} 11.340$ conhecida como Lei Maria da Penha, que recebeu tal denominação em homenagem a Maria da Penha, do estado do Ceará, que sofria violência doméstica. A lei garante a todas as mulheres que sofrem violência, o direito fundamental em viver em ambientes, onde ela tenha todo o seu direito a vida, saúde, a segurança e dignidade dentre outros, que possibilite a mesma exercerem plenamente sua cidadania, ser alguém que tem seus direitos garantidos por lei, tendo assim, a proteção do Estado, que se compromete a desenvolver políticas públicas de proteção à mulher, que conjuntamente com a família (PARADA M, 2009).

A violência pode ocorrer em diversos lugares no mundo, em qualquer classe social, raça e etnias. Por esse motivo a violência contra mulheres é entendida como um fenômeno social baseada nas desigualdades de gênero e não como uma consequência da pobreza ou do alcoolismo, como algumas pessoas entendem até hoje. Maria da Penha Fernandes, a brasileira que deu o nome á lei № 11.340, mostra como uma classe social abastada, com escolaridade superior também pode ser vítima de violência doméstica e familiar (BRASIL, 2013). No artigo $5^{\circ}$ da lei Maria da Penha a violência pode ser definida como violência doméstica e familiar contra a mulher qualquer ação ou omissão baseada no gênero que lhe cause morte, lesão, sofrimento físico, sexual ou psicológico e dano moral ou patrimonial (MINAYO MCS, et al., 2018).

Segundo levantamento feito no ano de 2017, foi evidenciado que por dia, cerca de doze mulheres foram assassinadas no Brasil, com aumento de dados de 6,5\% dos casos em relação a 2016, quando foram registrados 4.201 homicídios, dentre eles 812 feminicídios. Com isso, fechando o total de 4.473 de homicídios dolosos, ou seja, 946 casos de feminicídio. Colocando o Brasil em sétimo lugar no ranking de países em que as mulheres mais sofrem qualquer tipo de violência, dentre 87 nações, segundo a Organização Mundial de Saúde (OMS) (VELASCO C, et al., 2018).

A Atenção Básica é o primeiro nível de atenção em saúde e se caracteriza por um conjunto de ações de saúde, no âmbito individual e coletivo, que engloba a promoção e a proteção da saúde, a prevenção de agravos, o diagnóstico, o tratamento, a reabilitação, a redução de danos e a manutenção da saúde (BRASIL, 2020). Desta forma, se torna a porta de entrada de mulheres ao Sistema Único de Saúde (SUS), e são os profissionais de enfermagem os primeiros a entrarem em contato com as mulheres nos serviços de saúde, os enfermeiros dominam um papel de suma importância no atendimento da Violência Contra a Mulher (VCM). Além disso, geralmente mantêm um vínculo de longa duração com as usuárias, de maneira que a sua capacitação para manejar casos se torna crucial no atendimento da violência (BARALDI ACP, et al., 2012). 
O estágio curricular obrigatório ou supervisionado está inserido nas atividades de integração ensinoserviço e é apresentado como fundamental para a formação profissional dos estudantes e integradores do ensino-serviço em seus determinados cursos (BALDOINO AS e VERAS RM, 2016). Com isso, através da modalidade de ensino em serviço, relatada neste estudo, é possível perceber uma favorável melhora na qualificação para o atendimento, além disso, ocorre uma relação de troca de saberes entre discentes, docentes, profissionais do serviço de saúde e usuários do serviço, contribuindo assim para a formação de um perfil de profissional envolvido com a qualidade na saúde e que atenda os anseios da população (SILVA AF, 2011).

O relato de experiência teve como objetivo realizar ações educativas em saúde, abordando a Violência Contra a Mulher (VCM), para as usuárias do Sistema Único de Saúde de uma Unidade Básica de Saúde.

\section{RELATO DE EXPERIÊNCIA}

Trata-se de uma pesquisa descritiva, do tipo relato de experiência desenvolvida a partir da prática de educação em saúde realizada por acadêmicos do $7^{\circ}$ período do curso de bacharelado em Enfermagem do Centro Universitário do Estado do Pará (CESUPA). A referida prática foi executada a partir das aulas práticas da disciplina de Saúde Coletiva. A metodologia de ensino-aprendizagem definido a integração entre o ensino e o serviço através da inserção dos discentes no serviço de saúde, é favorável para a inserção de novas formas de organização do trabalho em saúde, favorecendo uma melhor qualificação para o atendimento (ALBUQUERQUE VS, et al., 2008).

A ação foi realizada em uma unidade básica de saúde (UBS). A ação educativa teve como público alvo mulheres usuárias do Sistema Único de Saúde (SUS) que frequentavam o serviço de Atenção Básica (AB) de uma Unidade Municipal de Saúde, com faixa etária entre 18 anos a 40 anos, que estavam na sala de espera da mesma para coleta do exame preventivo, na qual foi possível promover uma comunicação efetiva com o público presente.

Para a organização da prática de educação em saúde, iniciou- se com duas perguntas geradoras para compreender o nível de entendimento daquelas mulheres em relação à violência contra a mulher, tal como sentirmos o que pensam sobre o tema. $O$ uso de recursos visuais como cartazes e folders, foram usados com imagens relevantes sobre a temática de violência contra a mulher, e ainda, com informações de como proceder em situações de violência vivenciadas por elas.

As tecnologias consentem o registro, a viabilização do processo de aprendizagem de cada um e de todos os envolvidos. Mapeiam os progressos, apontam as adversidades, podem prever alguns caminhos para os que têm dificuldades específicas, elas facilitam como nunca antes múltiplas formas de comunicação horizontal, em redes, em grupos, individualizada (MORAN J, 2017). Desta forma, o uso de tecnologias ativas se torna uma ferramenta fundamental para o processo de ensino e aprendizagem.

Ao iniciar a prática de educação em saúde, as discentes fizeram as perguntas citadas acima. Em seguida, utilizando as tecnologias leves em saúde (cartazes e folders que foram distribuídos entre as mulheres). Enfim, houve a explicação pelas palestrantes sobre o que é a violência contra a mulher, seus tipos, como prevenir e proceder em situações de violência. Por fim, foram citadas algumas políticas públicas específicas para mulheres. Nesse momento, foi perceptível o vasto interesse das mulheres sobre o assunto, sendo possível também observar suas expressões de espanto quando fora esclarecido o que de fato se trata este assunto, de uma forma mais aprofundada, gerando uma boa interatividade do público durante toda a ação. No final foi realizada perguntas referentes ao assunto e algumas responderam o seu ponto de vista, o que permitiu a oportunidade de agregar mais ainda aos conhecimentos dela e de todos os ouvintes.

\section{DISCUSSÃO}

Durante a atividade de educação em saúde foi evidenciado junto as participantes que elas entendem como violência contra a mulher que quando se fala em agressão, não se deve pensar apenas em socos, tapas e chutes. A agressão também ocorre através de palavras, atitudes e manipulações que ferem a dignidade de toda e qualquer mulher. Para elas o fato de estar presa em um relacionamento abusivo é também não ter real dimensão da gravidade da situação em que pode ser acometida e ou exposta. 
$\mathrm{Na}$ ação, foi exposto o conceito geral de todos os tipos de violência contra mulher, como a Lei Maria da Penha n 11.340 de 07 de agosto de 2006, bem como mostrar como se fazer denúncias anônimas pelo Disque Denúncia $\mathrm{N}^{\circ} 180$. Ao fim da ação, algumas mulheres relataram que conheciam apenas a violência física, mas ao final disseram que foi possível absorver todos os outros tipos de violência contra mulher, como a violência Intrafamiliar e a doméstica através da apresentação.

Após a exposição e abordagem do assunto, pode-se perceber através de relatos das mulheres que muitas conheciam de forma ainda incipiente, e confuso o que na verdade vem sendo considerada uma forma de violência contra a mulher e as especificidades dos tipos de violência, porém mostraram-se interessadas em aprender e, no final, começaram a identificar casos vivenciados por pessoas de seu convívio familiar e suas próprias experiências.

"Achava que palavrões não eram considerado violência contra a minha pessoa, acreditava ser uma forma de desrespeito com a pessoa que se tem ao lado para uma convivência, na minha cabeça passava a violência como situações de tapas, ponta pés" (E1).

"Eu tenho que fazer todas as vontades dele, não pode usar um short curto, não posso ficar de conversa com colegas, família, para ser sincera nem visitar, quando teimo e faço seu que vai ter muita briga" (E2).

"Eu não posso nem visitar a minha mãe, tenho que ficar trancada dentro de casa e fazer todas as vontades dele, é um ciúme sem fim" (E3).

Ressalta-se a importância de atentar para a necessidade de melhor esclarecer e atualizar as mulheres quanto ao reconhecimento de um relacionamento abusivo, uma vez que, nas relações abusivas predomina o excesso de poder sobre o outro. Para alguns pesquisadores as mulheres devem ser esclarecidas algumas situações de ocorrência que podem indicar se você está em um relacionamento abusivo, tais como: o ciúme e possessividade exagerados, controle sob as decisões e ações das parceiras, querer isolar a parceira até mesmo do convívio com amigos e familiares, ser violento verbalmente e/ou fisicamente, pressionando e/ou obrigando a parceira a ter relações sexuais (BARRETTO SR, 2015).

Mesmo que qualquer pessoa, de qualquer gênero, possa vir a ser vítima de uma relação abusiva, de acordo com a psicóloga Barretto SR (2015), as principais vítimas, no Brasil, são as mulheres jovens. Independentemente do gênero, quem está em um relacionamento abusivo deve pedir ajuda psicológica especializada e contar com o apoio de amigos, familiares ou grupos específicos. Vale reforçar que a violência, psicológica e/ou física, contra quem quer que seja, constitui um crime.

Ao realizar a ação educativa, torna-se imprescindível para entender o nível de conhecimento para orientação e assim identificar possíveis casos de violência em um bairro onde prevalece a baixa renda, ou seja, onde a informação que deveria se fazer presente, muitas das vezes nem chega no local. Ter o mínimo de conhecimento sobre a violência contra a mulher e sobre os meios que a assegura é de suma importância para que os casos sejam amenizados, e que diante do entendimento sobre a temática sejam utilizados seus direitos. Na Lei $n^{\circ} 11.340$, de 7 de agosto de 2006 do artigo $3^{\circ}$ :

"Serão asseguradas às mulheres as condições para o exercício efetivo dos direitos à vida, à segurança, à saúde, à alimentação, à educação, à cultura, à moradia, ao acesso à justiça, ao esporte, ao lazer, ao trabalho, à cidadania, à liberdade, à dignidade, ao respeito e à convivência familiar e comunitária" (BRASIL, 2006)

Sendo assim, ao direcionar a população feminina acerca do que estão expostas e de seus direitos, há maior autonomia caso questionadas, possibilitando disseminar informações para as demais mulheres do seu convívio. Por isso, as políticas e ações de atendimento devem ser baseadas na atenção integral, com ética e qualidade, cuja interface da violência à mulher, priorize diretrizes interligadas à segurança, justiça e saúde, competindo ao profissional o preparo com reflexões e atuações multisetoriais e multidisciplinares, que incidam diretamente em impactos positivos da realidade atual (BANDEIRA LM, 2014). 
A violência contra a mulher em toda a suas formas: psicológica, física, moral, patrimonial, sexual, tráfico de mulheres - é um evento que alcança mulheres de diferentes classes sociais, origens, religiões, estado civil, escolaridade ou raça (GUIMARÃES MC e PEDROZA RLS, 2015). Torna-se necessário, portanto, que sejam implementadas políticas públicas acessíveis a todas as mulheres e que englobem todos os tipos de violência assim como os fatores que contribuem para sua disseminação.

A partir da relevância sobre a desigualdade de gênero evidenciou a importância em abordar a temática acerca dos contextos em que estão inseridas, tais quais com o enfoque nas diversas relações possibilitando compreender sobre feminilidade e masculinidade (BUTLER J, 2012).

Entende-se que a cultura machista ainda é muito evidenciada em nosso país e que a partir do momento em que se trabalha 0 combate desses agravantes com as crianças, que são o futuro, pode-se conseguir alterar a questão da violência contra a mulher. Partindo-se do princípio de se começam a aprender a importância do respeito às pessoas, se dar ao respeito e não temer a denúncia de situações vexatórias e abusivas de violência (SEGATO RL, 2011).

Partindo-se desse princípio reitera a importância da realização de orientações, esclarecimento e troca do conhecimento através da atuação das ações educativas sobre medidas de prevenção, considerando ser essenciais na busca de combate e coibição da violência doméstica e familiar contra a mulher. Esta oportunidade de atuar na prevenção é primordial para uma mudança de comportamento da sociedade, para que os alunos se tornem agentes transformadores e contribuam conosco na construção de uma sociedade melhor. O respeito ao outro deve estar dentro de todos nós, tem-se a certeza que o aprendizado foi marcante.

É importante ressaltar que as ações educativas em saúde é um dos meios mais amplos e oportunos para o combate à violência na comunidade, dessa forma o profissional deve buscar a execução de palestras em sala de espera com distribuição de folders, disponibilizando cartazes explicativos com imagens citando os locais de apoio onde a mesma pode efetuar a denúncia e requerer proteção como o Centro de Referência Especializado de Assistência Social o Centro de Referência de Assistência Social - CREAS (BENELLI SJ, 2016).

\section{CONSIDERAÇÕES FINAIS}

Por ser a atenção básica a porta de entrada do Sistema de Saúde ressalta-se a importância de realizar ações educativas para melhor atendimento do conhecimento sobre esta ocorrência da violência e das políticas pública a saúde das mulheres, esclarecendo e buscando minimizar os índices de morbimortalidade feminina. Entende-se que a ação educativa nos serviços de saúde deve ser um serviço prioritário como um compromisso de consciência dos profissionais de saúde na busca de melhor esclarecer a mulher sobre a violência doméstica, no atendimento de seus direitos e entender a ação educativa como um dever social das equipes de saúde, levando informações a comunidade no sentido de ampliar o conhecimento da população em geral sobre a violência.

\section{REFERÊNCIAS}

1. ALBUQUERQUE VS, et al. A integração ensino-serviço no contexto dos processos de mudança na formação superior dos profissionais da saúde. Revista brasileira de educação médica, 2008; 32(3), 356-362.

2. BARALDI ACP, et al. Violência contra a mulher na rede de atenção básica: o que os enfermeiros sabem sobre o problema. Revista Brasileira de Saúde Materno Infantil, 2012; 12(3): 307-31.

3. BARRETTO SR. Relacionamentos Abusivos: O que é e como lidar com essa situação. Repórter Unespin Relacionamentosago, 20, 2015.

4. BANDEIRA LM. Violência de gênero: a construção de um campo teórico e de investigação. Sociedade e Estado, 2014; 29(2), 449-469.

5. BENELLI SJ. O atendimento socioassistencial para crianças e adolescentes: perspectivas contemporâneas. São Paulo: Editora UNESP, 2016; $342 \mathrm{p}$.

6. BRASIL. Lei Maria da Penha. Lei ํ⒒340, de 7 de Agosto de 2006.

7. BRASIL. Ministério Público Federal. Procuradoria Federal dos Direitos do Cidadão (PFDC). Cartilha Maria da Penha e Direitos da Mulher. Brasília: Ministério Público Federal, 2013; 35p. 
8. BRASIL. Ministério da Saúde. Política Nacional de Redução da Morbimortalidade por Acidentes e Violências. Portaria GM/MS n 737 de 16 de maio de 2001. Diário Oficial da República Federativa do Brasil: Brasília, 2001; Seção 1 e, n 96.

9. BRASIL. Ministério da Saúde. Saúde em Família. Brasil: Atenção Primária. 2020.

10. BRASIL. Ministério da Saúde. Secretaria de Políticas de Saúde. Violência intrafamiliar: orientações para prática em serviço. Brasília: Ministério da Saúde, 2001; 96p.

11. BUTLER J. Problemas de gênero: Feminismo e subversão da identidade. 4nd ed. Rio de Janeiro: Civilização Brasileira. (Original publicado em 1990). 2012.

12. BALDOINO AS, VERAS RM. Análise das atividades de integração ensino-serviço desenvolvidas nos cursos de saúde da Universidade Federal da Bahia. Revista da Escola de Enfermagem da USP, 2016; 50: 017-024

13. GUIMARÃES MC, PEDROZA RLS. Violência contra a mulher: problematizando definições teóricas, filosóficas e jurídicas. Psicol. Soc. Belo Horizonte, 2015; 27(2).

14. MINAYO MCS, et al. Institucionalização do tema da violência no SUS: avanços e desafios. Ciência \& Saúde. 2018; 23(6).

15. MORAN J. 2017. Metodologias ativas e modelos híbridos na educação. In: YAEGASHI S, et al. (Orgs). Novas tecnologias digitais: reflexões sobre mediação, aprendizagem e desenvolvimento. Curitiba: CRV, 23-35.

16. MORAIS FRR, et al. A importância do PET-Saúde para a formação acadêmica do enfermeiro. Trab. Educ. Saúde. Rio de Janeiro, 2012; 10(3).

17. PARADA M. Cartilha sobre violência contra a mulher. São Paulo: Ordem dos Advogados do Brasil. Comissão da Mulher Advogada. Seção de São Paulo, 2009.

18. SEGATO RL. 2011. Género y colonialidad: en busca de claves de lectura y de um vocabulario estratégico descolonial. In K. Bidaseca \& V. V. LABA (Eds.), Feminisimos y Poscolonialidad. Descolonizando el feminismo desde y en América Latina. Buenos Aires: Godot, 2011; pp. 17-48.

19. SILVA AF. O enfoque da promoção da saúde nas atividades de extensão universitária na área da saúde. São Paulo: USP, 2011.

20. VELASCO C, et al. 2018. In: Cresce o no de mulheres vítimas de homicídio no Brasil; dados de feminicídio são subnotificados. Monitor da violência. Portal G, 1, 07. 2018. Disponível em: https://g1.globo.com/monitor-daviolencia/noticia/cresce-n-de-mulheres-vitimas-de-homicidio-no-brasil-dados-de-feminicidio-sao-subnotificados.ghtml. Acesso em: 7 mar. 2020. 